\title{
Diagnostic validity of the use of ICDAS II and DIAGNOdent pen verified by micro-computed tomography for the detection of occlusal caries lesions - an in vitro evaluation
}

\author{
Elzbieta Luczaj-Cepowicz ${ }^{1} \cdot$ Grazyna Marczuk-Kolada $^{1} \cdot$ Marta Obidzinska $^{1} \cdot$ Jarosław Sidun $^{2}$
}

Received: 17 October 2018 / Accepted: 26 February 2019 / Published online: 14 June 2019

(C) The Author(s) 2019

\begin{abstract}
The aim of this study is to assess the extent of early carious lesions using the International Caries Detection and Assessment System (ICDAS) II and DIAGNOdent pen compared with microCT examination. Forty-eight molars and premolars were qualified for the study. The visual and the DIAGNOdent pen device examinations were carried out by two examiners. The actual extent of the lesions was determined using micro-CT examination. The optimal cutoff test value was determined using the Youden index. For the two methods, inter- and intra-examiner reproducibility was calculated using intraclass correlation coefficient. The sensitivity, specificity, and accuracy of these methods were compared using the mid-P McNemar test. The level of significance was set at $p<0.05$. In terms of the enamel threshold for the ICDAS II scale, insignificantly higher mean evaluated parameters were noticed in comparison with the DIAGNOdent pen device. For the dentin threshold, all the assessed parameters had higher mean values on the ICDAS II scale compared with the DIAGNOdent pen. The optimal cutoff points of the enamel and dentin thresholds are lower than that suggested by the manufacturer. The ICDAS II and the DIAGNOdent pen device were characterized by high inter - and intra-observer reproducibility of the test results. To improve the diagnostic efficiency of the DIAGNOdent pen, modifying the cutoff values recommended by the manufacturers should be considered. After modifying the cutoff values, the combination ICDAS II and DIAGNOdent pen device would be the better choice in order to detect caries on occlusal surfaces.
\end{abstract}

Keywords Caries detection · ICDAS II · DIAGNOdent pen $\cdot$ MicroCT $\cdot$ Fluorescence

\section{Introduction}

The basic assumption of modern dentistry is the early detection of initial carious lesions. The diagnosis of these lesions and the assessment of their severity give clinicians' considerable difficulties resulting from the diversified fissure and pit morphology as well as the widespread use of fluoride compounds [1-3]. The basis for caries' diagnosis is a meticulous visual examination. A visual examination is based on a

Grazyna Marczuk-Kolada

grazyna.kolada@umb.edu.pl

1 Department of Pedodontics, Medical University of Bialystok, Waszyngtona Str. 15a, 15-297 Bialystok, Poland

2 Faculty of Mechanical Engineering, Bialystok University of Technology, Bialystok, Poland subjective assessment dependent on the examiner's skills and experience. It is characterized by high specificity, but its sensitivity, reliability, and reproducibility are low $[1,4]$. The International Caries Detection and Assessment System (ICDAS) is used to diagnose carious lesions and was developed to standardize diagnosis and clinical management [5]. The diagnosis of these lesions and the assessment of their severity give clinicians' considerable difficulties resulting from the diversified fissure and pit morphology as well as the widespread use of fluoride compounds [1-3]. Novel technologies have been investigated as diagnostic tools in order to identify and quantify initial demineralization. Along with visual detection systems, it can be referred to fluorescence assessment which can be considered a suitable method. A possibility is the detection of the emitted fluorescence after a modulated red light is applied, because caries-induced changes in teeth lead to increased fluorescence at specific excitation wavelengths. Hibst et al. [6] found that porphyrins are 
responsible for the fluorescence level in carious tissues, which are released in caries lesions by cariogenic bacteria when exposed to a $655-\mathrm{nm}$ red light. The intensity of the fluorescence indicates the depth of the caries lesion. This was taken advantage of the DIAGNOdent pen device (Kavo, Biberach, Germany). When assessing the effectiveness of diagnostic methods, their sensitivity, specificity, accuracy as well as their reproducibility and unambiguity should be taken into account [7]. In clinical practice, interpretation of DIAGNOdent pen indications is connected to cutoff limits. Some studies pertaining to cutoff points are not always in accordance with those suggested by the device manufacturer $[4,8-10]$. The values of these parameters should be verified by a reference examination, referred to as the gold standard. In in vitro studies, the actual extent of lesions is most often assessed by histological examination [11-13]. According to the authors, a non-destructive method of visualizing the extent of carious damage can be microcomputed tomography (microCT) $[14,15]$. It is a modified version of computed tomography, enabling noninvasive 3-D imaging of tooth tissues. In recent years, it has been used in laboratory research in the field of dentistry, for measuring the mineral density of enamel and dentin, evaluating cortical bone and the sealing ability of fillings of carious cavities and root canals $[12,13,15,16]$. The use of this method in clinical practice has some limitations, such as high radiation doses, long scanning time, and image processing as well as the high cost of the device with software [16].

The aim of this in vitro study was to investigate the extent of occlusal early carious lesions in enamel and dentin using the ICDAS II, DIAGNOdent pen compared with microCT examination.

\section{Materials and methods}

The research was approved by the Ethics Committee of the Medical University of Bialystok (no. R/I/002/170/2016).

\section{Preparation of samples}

Eighty teeth were extracted as a result of orthodontic, periodontal, and surgical indications. Immediately after the procedure, the teeth were rinsed under running water and then stored in a freezer $\left(-18{ }^{\circ} \mathrm{C}\right)$ for 2 months. After a 4-h defrosting, the teeth roots surfaces were cleaned using a dental scaler. Next, the occlusal surfaces were cleaned using a lowspeed tip with a brush and toothpaste. After thoroughly rinsing the remains of the toothpaste with a water spray and air-drying, the teeth were individually placed in a wax plate, and they were thawed in an incubator $\left(24{ }^{\circ} \mathrm{C}\right.$ and $100 \%$ humidity) for $4 \mathrm{~h}$. Each tooth remained in these conditions until the examination. Before the examination, the occlusal surface was moistened with physiological saline (wet examination) and then dried for $5 \mathrm{~s}$ (dry examination).

The inclusion criteria of occlusal tooth surfaces in the study were no signs of caries, noticeable opacity, or white/brown discoloration that did not match the appearance of healthy enamel. The exclusion criteria were the following: the presence of fissure sealants, fillings, hypomineralization, occlusoproximal lesions, or lesions with cavitation. From the extracted teeth, 48 molars (including third molars) and premolars were qualified for the study, and 32 teeth were used for calibration.

\section{Visual examination (ICDAS II)}

The visual examination was carried out in artificial lighting from the unit lamp, selecting one suspected spot on each occlusal surface. The tooth surfaces were soaked with physiological saline and evaluated under moist conditions and then after drying for $5 \mathrm{~s}$.

The ICDAS II system (International Caries Detection Assessment System) was used:

code 0 - sound tooth surface

code 1 -first visual change in enamel: $1 \mathrm{w}$ (white) or $1 \mathrm{~b}$ (brown)

code 2 -distinct visual change in enamel: $2 \mathrm{w}$ (white) or $2 \mathrm{~b}$ (brown)

code 3-localized enamel breakdown due to caries with no visible dentin or underlying shadow

code 4-underlying dark shadow from dentin with or without localized enamel breakdown

code 5-distinct cavity with visible dentin

code 6 - extensive distinct cavity with visible dentin $[17,18]$

Code 3 was the cutoff threshold for dentin lesions. Prior to the visual examination, both examiners used training software on the ICDAS web site [19]. After training, the two dentists examined the occlusal surfaces of the teeth separately in two sessions, with a 2-week interval. The second examiner evaluated the teeth in the same sequential order. Between examinations, the teeth were frozen and thawed, as described above. The measurements were made independently, and the examiners were blinded for the peer's scores. The occlusal surfaces of stabilized teeth were photographed with a digital camera (Canon Eos 450d, $100 \mathrm{~mm}, \mathrm{~F} 2.8$ EF macro) mounted on a tripod. Then, using a graphic program (GIMP 2.8.22), selected places were marked on the digital images to be able to locate them again more easily (Fig. 1a). This procedure enabled precise determination 
Fig. 1 Original photo image of the third lower molar with one selected occlusal site (a), images of micro-CT are as follows: coronal (b), sagittal (c), axial (d)

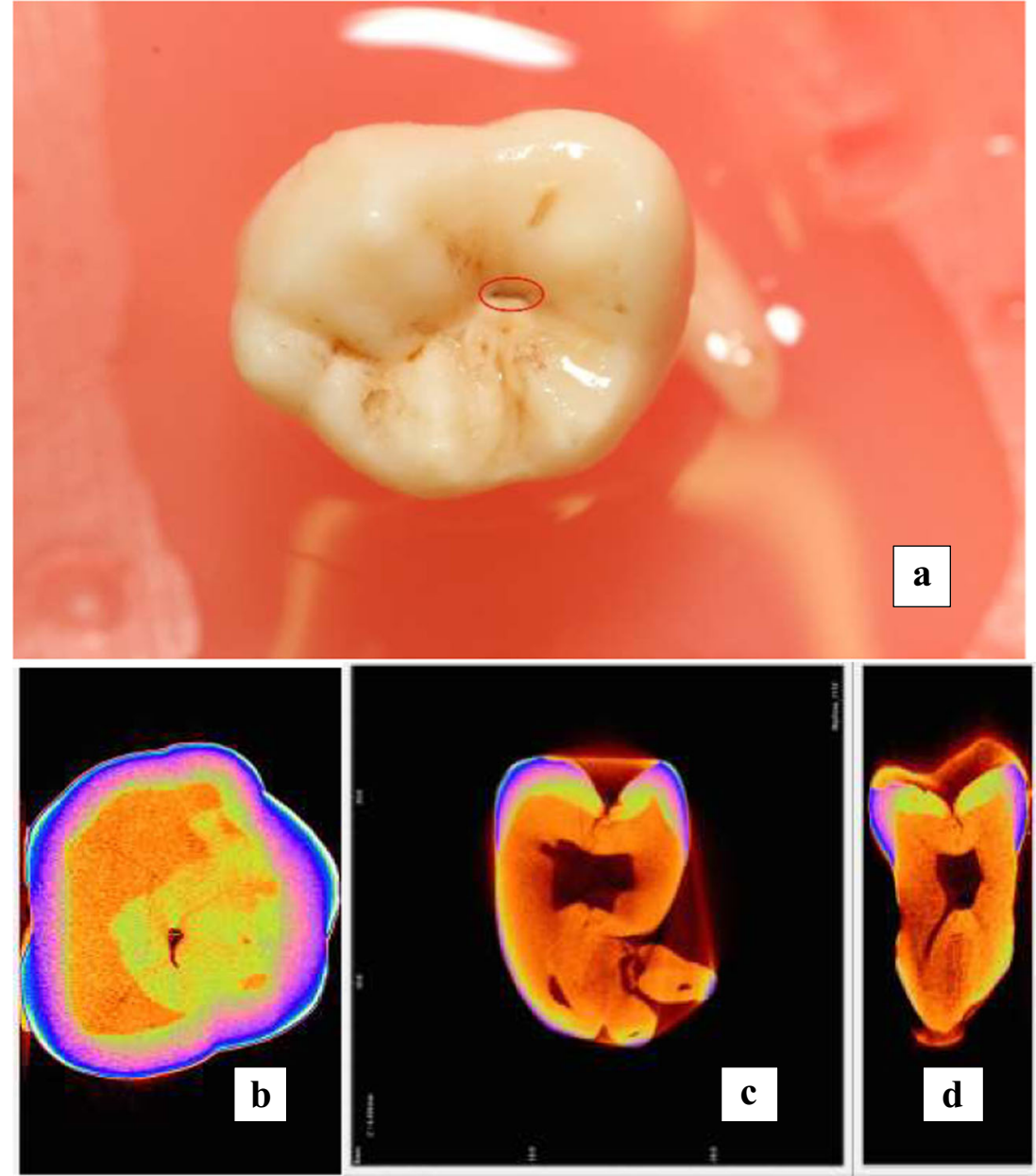

of the location of the examined place at every stage of the experiment. The examined teeth were given subsequent ordinal numbers.

\section{DIAGNOdent pen examination}

After the digital imaging, an examination was carried out using the DIAGNOdent pen device (Kavo, Biberach, Germany). After attaching the probe for examining occlusal surfaces, calibration was carried out in accordance with the device manufacturer's recommendations. Double calibration was done and then the probe was applied at the designated location, and rotational movements were performed to evaluate all fissure walls and to correctly determine the maximum value. The obtained results were interpreted in accordance with the scale developed by the manufacturer $[6,10]$ :

- 0-13-sound

- 14-20-enamel caries

- 21-29 - caries in dentin-enamel junction

- >29-dentin caries
Assessments were provided twice by the same two examiners, with a 14-day interval between measurements.

\section{Micro-CT examination}

The actual extent of the lesions was determined using microcomputed tomography (micro-CT) examination, which was done at the Faculty of Mechanical Engineering of the Bialystok Technical University. The assessment was done using the SkyScan 1172 microtomograph (Bruker, Kontich, Belgium) (59 kV; $167 \mathrm{~mA} ; 13.59 \mathrm{~mm}$, pixel size; $900 \mathrm{~ms}$, exposure time; angle of rotation during scanning, every $0.2^{\circ}$; scan time of one object approx. 03:10 h). After 3-D reconstruction in NRecon software (version 1.7.0.4), coronal, sagittal, and axial planes were obtained (thickness of the imaging layer $0.009 \mathrm{~mm}$ ). DataViewer and its functions, such as brightness change, color mode, and magnification, were used for image analysis. The previously marked place was located on the coronal sections. Then, the marked places were interpreted twice (at 7-day intervals) by two researchers who did not participate in the previously conducted diagnostic tests. 
All teeth were qualified to one of five groups according to the scale proposed by Hintze et al. [20]:

1. 0 - sound

2. E1-radiolucency in outer half of enamel

3. E2-radiolucency in inner half of enamel

4. D1-radiolucency in outer third of dentine

5. D2-radiolucency in inner two thirds of dentine

Diagnostic parameters were assessed for two advancement thresholds, enamel and dentin. For the enamel threshold, all current carious lesions with radiological E1, E2, D1, and D2 progression were considered positive, while 0 was assumed to be sound. For dentin lesions (dentin threshold), radiological progression of D1 and D2 was considered to be the presence of disease, while for negative cases $0, \mathrm{E} 1$, and $\mathrm{E} 2$.

\section{Statistical analysis}

Statistical analysis was performed using IBM SPSS Statistics 20.0 software (StatSoft, Cracow, Poland). Both examinations were repeated 2 weeks later to assess the intra- and interexaminer reproducibility. For the two methods, interexaminer reproducibility was calculated for the examiners, and intra-examiner reproducibility was calculated for the trained examiners using intraclass correlation coefficient (ICC). The sensitivity, specificity, accuracy, positive predictive value (PPV), and negative predictive value (NPV) of the tested methods were determined in relation to the cutoff values recommended by the manufacturer [21,22]. The sensitivity, specificity, and accuracy of these methods were compared using the mid-P McNemar test [21-23]. Correlations of the results of the microCT, visual, and DIAGNOdent pen examinations (nonparametric Spearman's correlation) were evaluated. The diagnostic value of the methods was determined by creating ROC (receiver operating characteristic) curves, which is a graphic representation of the relationship between the percentage of true positive test results (sensitivity) and the percentage of false positives (1-specificity). The curve created in this way, and in particular, the area under it (AUC, area under the curve), enables direct assessment of the diagnostic power of the tested method. It also applies to determining the optimal cutoff point that divides the assessed population into two groups: one in which disease is present and one with no disease. The optimal cutoff test value (with the highest possible sensitivity at high specificity) was determined using the Youden index. The Youden index $(J)$ is a function of sensitivity and specificity defined by $J=$ maximum \{sensitivity + specificity-1\}. This index ranges between 0 and 1 , with values close to 1 indicating that the method effectiveness is relatively large [24].

For both methods, cutoff points were found for which the Youden index was the highest, as well as method sensitivity and specificity for the new cutoff values. These parameters were determined separately for the enamel threshold and the dentin threshold. Results were considered statistically significant when the calculated probability of $p<0.05$.

\section{Results}

For all data, intraclass-correlation coefficients (ICC) for intraand inter-examiner reproducibility were high and were between $0.73-0.88$ for ICDAS II, $0.75-0.87$ for DIAGNOdent pen, and $0.83-0.91$ for microCT (Table 1).

The cross-tabulation between the ICDAS II codes, DIAGNOdent pen and the corresponding microCT depth is demonstrated in Table 2. MicroCT examination revealed that of the 48 occlusal examination sites, 8 were sound (0), 4 had caries extending up to the outer half of the enamel (E1), 20 had caries extending into the inner half of the enamel (E2), 15 had caries in the dentin outer one third (D1), and 1 site had caries in the $1 / 3$ middle dentin (D2).

Table 3 presents the sensitivity, specificity, positive predictive value (PPV), negative predictive value (NPV), accuracy, and Spearman's rank correlation coefficient $\left(r_{\mathrm{s}}\right)$ for ICDAS, DIAGNOdent pen, and microCT at the enamel and dentin thresholds. In terms of the enamel threshold for the ICDAS II, insignificantly higher mean values of sensitivity, accuracy, PPV, and NPV were noticed in comparison with the DIAGNOdent pen device. Only the specificity was
Table 1 Intraclass correlation coefficient (ICC) values for interand intra-examiner reproducibility for three methods and $95 \%$ confidence intervals in parentheses

\begin{tabular}{|c|c|c|c|c|c|c|}
\hline \multirow[b]{2}{*}{ Method } & \multicolumn{3}{|c|}{ Inter-examiner } & \multicolumn{3}{|c|}{ Intra-examiner } \\
\hline & Examiner & ICC & (95\% C.I) & Examination & ICC & (95\% C.I.) \\
\hline \multirow[t]{2}{*}{ ICDAS II } & 1 & 0.76 & $(0.691-0.822)$ & 1 & 0.77 & $(0.695-0.824)$ \\
\hline & 2 & 0.88 & $(0.838-0.910)$ & 2 & 0.73 & $(0.654-0.798)$ \\
\hline \multirow[t]{2}{*}{ DIAGNOdent pen } & 1 & 0.85 & $(0.767-0.899)$ & 1 & 0.75 & $(0.574-0.844)$ \\
\hline & 2 & 0.87 & $(0.819-0.909)$ & 2 & 0.78 & $(0.647-0.858)$ \\
\hline \multirow[t]{2}{*}{ microCT } & 1 & 0.83 & $(0.771-0.872)$ & 1 & 0.87 & $(0.823-0.902)$ \\
\hline & 2 & 0.85 & $(0.799-0.888)$ & 2 & 0.91 & $(0.881-0.935)$ \\
\hline
\end{tabular}


insignificantly lower for the ICDAS II. For the dentin threshold, all the assessed parameters had higher mean values on the ICDAS II compared with the DIAGNOdent pen, but only accuracy was statistically significant $(p<0.05)$.

A summary of the values of sensitivity, specificity, area under the curve (AUC), and cutoff points with reference to the thresholds provided by the manufacturer as well as our own (the highest Youden index value) is presented in Table 4. When verified using microCT, the DIAGNOdent pen results suggested that at a value above 5.88 enamel caries occur. This value is lower than the device manufacturer indicated (>13). It should be noted that, with regard to the microCT examination, the DIAGNOdent pen was characterized by very high sensitivity for the optimal cutoff point of the enamel threshold. The obtained highest values of the Youden index for dentin lesion detection indicate their occurrence at DIAGNOdent pen indications above 19.5. Similar to enamel lesions, this value is lower than that suggested by the manufacturer (>29).

\section{Discussion}

Diagnosing lesions located on occlusal surfaces is not a simple task. In vitro studies should be conducted in a way as close as possible to clinical conditions. Various factors, and above all, the way samples are stored, may affect the obtained results $[25,26]$. Substance storage time could change the fluorophore concentrations in samples as well as the optical properties of hard tissues. According to the results of other studies, storing samples in low temperatures, without any kind of media (storing solution), creates close to clinical conditions. The most common causes of this conjuncture are the way caries spread, which hinders clinical evaluation, and the widespread use of preparations containing fluoride ions, causing increased mineralization of the superficial enamel layers [27, 28]. In in vitro studies, the actual extent of lesions is most often assessed by histological examination, which is not without flaws. First, during the preparation of thin sections of tooth tissues, the area with the highest advancement of carious lesions or irreversibly damaged samples could be omitted [11-13]. In the current study, the results obtained using the ICDAS II criteria and the DIAGNOdent pen were compared with micro-computed tomography examination. Micro-computed tomography (microCT) is a modified version of computed tomography, enabling noninvasive 3-D imaging of tooth tissues. The use of microCT as the gold standard in research on caries diagnosis methods has been evaluated by, among others, Soviero et al. [13]. They showed that the results obtained by histological and microCT examinations are comparable.
However, the advantage of microCT over histological examination is lack of tissue destruction during scanning with a microtomograph. Other authors [14-16] also considered microCT, the preferred gold standard for assessing the depth of carious lesions in in vitro conditions. Based on microCT, our study showed that the highest percentage of cases had lesions located in the inner $1 / 2$ enamel layer $(41.67 \%)$, then in the outer $1 / 3$ dentin layer $(31.25 \%)$. Healthy teeth were noted in $16.67 \%$ of cases, lesions in the outer $1 / 3$ enamel layer, and the middle dentin layer accounted for $8.33 \%$ and $2.08 \%$, respectively.

According to Braga et al., the effectiveness of ICDAS II caries classification is comparable to assessment using the WHO criteria, while being more time-consuming [29]. Numerous scientists around the world evaluated its effectiveness in determining carious lesion severity, both in primary and secondary dentition, in clinical and in vitro conditions, as well as the factors affecting the accuracy of this evaluation [3, 30-37]. In the assumption of their paper, Reis et al. put forward the hypothesis that evaluations done outside the oral cavity create better diagnostic conditions than in the patient's oral cavity [38]. The examination was done on the third molars qualified for extraction, assessing 110 selected sites. After removal, teeth were stored in isotonic saline solution. After conducting their study, they found that differences in in vivo and in vitro results were negligible, and in the case of using the visual method, they did not occur at all. Regardless of the study conditions, ICDAS II parameters, such as sensitivity, specificity, accuracy, PPV (positive predictive value) or NPV (negative predictive value), were very high. The efficacy of this classification was determined for the enamel threshold of lesion advancement, as well as only dentin.

From the numerous publications regarding the efficacy of the ICDAS II system, only two, similarly to the present study, used microCT to assess the real extent of the lesions $[13,16]$. Özkan et al. were the only ones to use microCT in their study to assess the occlusal surfaces of permanent molar and premolar teeth [16]. These authors noted similar rates of the extent of carious lesions to ours. They obtained a sensitivity of detecting enamel lesions at a level of 0.93 and 0.97 . The results of our study for the same threshold reached a slightly lower value, 0.85 . The remaining authors, who carried out the studies in in vitro conditions, used histological evaluation as a verification method. While conducting a study on a similar group of teeth, Iranzo-Cortez et al. reported very similar sensitivity of the ICDAS II to our results [33]. Achilleos et al. obtained similar results, a sensitivity of 0.80 and 0.86 for these types of lesions [30]. We noted high specificity $(0.75)$ for the enamel threshold compared with other authors [15]. High specificity values of the ICDAS II were also noted by Iranzo-Cortes et al. and Jablonski-Momeni et al. [33, 34]. 
Table 2 Cross-tabulation for ICDAS II and DIAGNOdent pen devices with the corresponding microCT

\begin{tabular}{|c|c|c|c|c|c|c|c|c|c|c|}
\hline \multirow[t]{2}{*}{ ICDAS II } & \multirow[t]{2}{*}{$n(\%)$} & \multicolumn{4}{|c|}{ DIAGNOdent pen } & \multicolumn{5}{|l|}{ microCT } \\
\hline & & $0-13(0)$ & $14-20(\mathrm{E} 1)$ & $21-29$ (E2) & $>29(\mathrm{D} 1, \mathrm{D} 2)$ & 0 & $\begin{array}{l}1 \\
\text { (E1) }\end{array}$ & $\begin{array}{l}2 \\
\text { (E2) }\end{array}$ & $\begin{array}{l}3 \\
\text { (D1) }\end{array}$ & $\begin{array}{l}4 \\
\text { (D2) }\end{array}$ \\
\hline 0 & $12(25.00)$ & 10 & 2 & 0 & 0 & 6 & 2 & 4 & 0 & 0 \\
\hline $1(\mathrm{E} 1)$ & $14(29.17)$ & 5 & 6 & 0 & 3 & 1 & 1 & 11 & 1 & 0 \\
\hline $2(\mathrm{E} 2, \mathrm{D} 1)$ & $8(16.67)$ & 2 & 1 & 4 & 1 & 1 & 1 & 3 & 2 & 1 \\
\hline 3 (D2) & $14(29.17)$ & 2 & 2 & 3 & 7 & 0 & 0 & 2 & 12 & 0 \\
\hline Total $n(\%)$ & $48(100.00)$ & $19(39.58)$ & $11(22.92)$ & $7(14.58)$ & $11(22.92)$ & $8(16.67)$ & $4(8.33)$ & $20(41.67)$ & $15(31.25)$ & $1(2.08)$ \\
\hline
\end{tabular}

In modern dentistry, the ability to detect dentin lesions is an extremely important characteristic of the diagnostic methods. It allows to determine the optimal time to initiate invasive treatment. In the current study, we showed that evaluating such lesions using the ICDAS II scale is characterized by lower sensitivity and higher specificity compared with those obtained for the enamel threshold. A similar tendency was observed in the studies of Özkan et al., in which the sensitivity of dentin lesion detection was lower than that of enamel, while specificity was higher [16]. The results obtained in the current study regarding the specificity of the ICDAS II differed from those described by Rodrigues et al. [37], but corresponded with the findings of other researchers [16, 30].

The high values of reproducibility and agreement obtained in our study indicate the possibility of using the ICDAS II to monitor carious lesions and assess the effectiveness of preventive treatments. The intra-examiner reproducibility in this study was high and similar to that presented by other authors [33]. Similarly to our study, scientists involved in the assessment of ICDAS II observed inter-examiner reproducibility between 0.62 and $0.82[11,16,30]$. The results obtained in our study, determined using the intraclass correlation coefficient, correspond with these reports despite a different data analysis method.

The possible clinical use of the DIAGNOdent pen is associated with specific cutoff values that suggest to the doctor the extent of carious lesions and the appropriate therapeutic management. Clinicians' therapeutic decisions are complicated by with the existence of several thresholds, proposed not only by manufacturers but also by authors of in vivo [39] and in vitro $[8,10]$ studies.

In the present study, the parameters of this diagnostic method were evaluated using the guidelines contained in the device manual as well as on the basis of the highest Youden index values used to determine the optimal thresholds. These parameters were determined first for the enamel threshold, where a score above 13 indicated the presence of lesions in accordance with the manufacturer's recommendations. The same cutoff value was adopted by Aktan et al. [1]. In the in vitro study, they showed a sensitivity of 0.65 , which was comparable to that obtained in the current study. Jablonski-Momeni et al. noted a higher sensitivity of the examination (0.83) with the DIAGNOdent pen, however, the accepted threshold was $>6$ [9].

Table 3 Sensitivity, specificity, accuracy, and positive and negative predictive values of ICDAS II and DIAGNOdent pen compared with the microCT at the enamel and dentin thresholds

\begin{tabular}{|c|c|c|c|c|c|c|}
\hline & Sensitivity & Specificity & Accuracy mean (SD) & PPV & NPV & $r_{\mathrm{s}}$ \\
\hline \multicolumn{7}{|l|}{ Enamel threshold } \\
\hline ICDAS II & $\begin{array}{l}0.85 \\
(0.71-0.93)\end{array}$ & $\begin{array}{l}0.75 \\
(0.41-0.93)\end{array}$ & $\begin{array}{l}0.83 \\
(0.70-0.91)\end{array}$ & $\begin{array}{l}0.94 \\
(0.82-0.98)\end{array}$ & $\begin{array}{l}0.50 \\
(0.25-0.75)\end{array}$ & $\begin{array}{l}0.67 \\
(p<0.0001)\end{array}$ \\
\hline DIAGNOdent pen & $\begin{array}{l}0.70 \\
(0.55-0.82)\end{array}$ & $\begin{array}{l}0.88 \\
(0.53-0.98)\end{array}$ & $\begin{array}{l}0.73 \\
(0.59-0.83)\end{array}$ & $\begin{array}{l}0.97 \\
(0.83-0.99)\end{array}$ & $\begin{array}{l}0.37 \\
(0.19-0.59)\end{array}$ & \\
\hline \multicolumn{7}{|l|}{ Dentin threshold } \\
\hline ICDAS II & $\begin{array}{l}0.75 \\
(0.51-0.90)\end{array}$ & $\begin{array}{l}0.94 \\
(0.80-0.98)\end{array}$ & $\begin{array}{l}0.88^{\mathbf{a}} \\
(0.75-0.94)\end{array}$ & $\begin{array}{l}0.86 \\
(0.60-0.96)\end{array}$ & $\begin{array}{l}0.88 \\
(0.73-0.95)\end{array}$ & $\begin{array}{l}0.70 \\
(p<0.0001)\end{array}$ \\
\hline DIAGNOdent pen & $\begin{array}{l}0.44 \\
(0.23-0.67)\end{array}$ & $\begin{array}{l}0.88 \\
(0.72-0.95)\end{array}$ & $\begin{array}{l}0.73^{\mathrm{a}} \\
(0.59-0.83)\end{array}$ & $\begin{array}{l}0.64 \\
(0.35-0.85)\end{array}$ & $\begin{array}{l}0.76 \\
(0.60-0.87)\end{array}$ & \\
\hline
\end{tabular}

${ }^{\text {a }}$ Significant difference $(\mathrm{McNemar}$ test $p<0.05)$

$r_{\mathrm{s}}$, Spearman's rank correlation coefficient 
Table 4 The area under the ROC curve, sensitivity and specificity, and corresponding cutoff points for enamel and dentin thresholds according to the manufacturer and highest value of the Youden index

\begin{tabular}{lllll}
\hline & $\begin{array}{l}\text { Sensitivity/specificity } \\
\text { mean }\end{array}$ & AUC & 95\% C.I.(AUC) & $p$ (AUC=0.5) \\
\hline $\begin{array}{l}\text { Enamel threshold } \\
\text { Cutoff point }>13^{*}\end{array}$ & $0.70 / 0.88$ & & & \\
$\quad$ Cutoff point $>5.88 * *$ & $0.93 / 0.75$ & & $(0.777-1.001)$ & 0.0001 \\
Dentin threshold & & & \\
Cutoff point $>29 *$ & $0.44 / 0.88$ & 0.77 & $(0.624-0.909)$ & 0.0002 \\
Cutoff point $>19.5 * *$ & $0.75 / 0.75$ & & \\
$*$ Cutoff points according to the manufacturer & & & \\
$* *$ Cutoff points at highest value of Youden index & &
\end{tabular}

In 2013, Gimenez et al. published a review of the literature on diagnostic methods using fluorescence [5]. Eight articles concerned the detection of initial carious lesions on the occlusal surfaces of permanent teeth using the DIAGNOdent pen. The sensitivity of the device in the aforementioned studies ranged from 0.63 to 0.89 , while specificity was $0.50-0.96$. When presenting the results, the authors of the review did not take into account, however, what cutoff values were used in the analyzed studies.

In a study published in 2017, on this issue, Iranzo-Cortes et al. noted a specificity of 0.53 [33]. When evaluating 64 occlusal surfaces, they found that the detection efficiency of initial carious lesions was higher when the ICDAS II and DIAGNOdent pen methods were combined compared with using these methods alone. In addition, they recorded positive (PPV) and negative (NPV) predictive values similar to those obtained in the present study.

Our results when using the DIAGNOdent pen showed lower sensitivity values of detecting dentin compared with enamel lesions. Some other authors made similar observations [1, 5, 9]. In our study, the cutoff value for the detection of dentin lesions was 29 , in accordance with the device instructions. We found no paper in which the authors used the same cutoff point. Researchers who classified dentin lesions when the indication value was above 17 noted a sensitivity ranging $0.78-0.82[9,37]$.

In the current study, we obtained lower values of this parameter. Aktan et al., as well as scientists from Switzerland and Germany, despite using a lower cutoff value $(>20)$, found lower sensitivity and specificity [1, 9, 37]. Rodrigues et al. determined the accuracy of the DIAGNOdent pen examination at 0.64 , which was slightly lower than the results we obtained [37]. The intra-examiner reproducibility in our study was high. Rodrigues et al. presented nearly identical results for this parameter [37].

The next parameter assessed in this paper was the area under the ROC curve (AUC). We found that in the case of the DIAGNOdent pen, the value for the enamel threshold was 0.89 and the dentin threshold 0.77 when adhering to the manufacturer's guidelines. These values indicate the high diagnostic value of the device, which is confirmed by other authors [9,
$16,33,37,40]$. Analysis of the Youden index suggests that the value above which enamel caries occur is 5.88 while dentin 19.5. These are lower values than those recommended by the manufacturer, but they are confirmed in the literature [9, 37] that the enamel threshold is higher than in our study and closer to the dentin threshold $[4,8]$.

The different composition of sample groups should be taken into consideration when translating the experiences into clinical practice [41]. In our study, we examined premolars and molars (including third molars). The differences in morphology of occlusal surfaces of investigated teeth may be a possible limitation of the present study.

\section{Conclusions}

In summary, it can be concluded that the ICDAS II system and the DIAGNOdent pen device were characterized by high inter- and intra-observer reproducibility of the test results. To improve the diagnostic efficiency of the DIAGNOdent pen, modifying the cutoff values recommended by the manufacturers should be considered.

Acknowledgement The study was performed at the Department of Pedodontics Medical University of Bialystok, Poland and Faculty of Mechanical Engineering, Bialystok University of Technology, Poland.

Funding The authors had received research grant from Medical University of Bialystok (No. N/ST/MN/16/001/1170).

\section{Compliance with ethical standards}

Conflict of interest The authors declare that they have no conflict of interest.

Ethical approval The research was approved by the Ethics Committee of the Medical University of Bialystok, Poland (No. R/I/002/170/2016).

Informed consent For this type of study, formal consent is not required.

Open Access This article is distributed under the terms of the Creative Commons Attribution 4.0 International License (http:// 
creativecommons.org/licenses/by/4.0/), which permits unrestricted use, distribution, and reproduction in any medium, provided you give appropriate credit to the original author(s) and the source, provide a link to the Creative Commons license, and indicate if changes were made.

\section{References}

1. Aktan AM, Cebe MA, Ciftci ME, Karaarslan ES (2012) A novel LED-based device for occlusal caries detection. Lasers Med Sci 27: 1157-1163. https://doi.org/10.1007/s10103-011-1020-0

2. Novaes TF, Matos R, Gimenez T, Braga MM, Benedetto MS, Mendes FM (2012) Performance of fluorescence-based and conventional methods of occlusal caries detection in primary molars an in vitro study. Int J Paediatr Dent 22:459-466. https://doi.org/10. 1111/j.1365-263X.2011.01217.x

3. Souza JF, Boldieri T, Diniz MB, Rodrigues JA, Lussi A, Cordeiro RCL (2013) Traditional and novel methods for occlusal caries detection: performance on primary teeth. Lasers Med Sci 28:287-295. https://doi.org/10.1007/s10103-012-1154-8

4. Lussi A, Megert B, Longbottom C, Reich E, Francescut P (2001) Clinical performance of a laser fluorescence device for detection of occlusal caries lesions. Eur J Oral Sci 109:14-19. https://doi.org/10. 1034/j.1600-0722.2001.109001014.x

5. Gimenez T, Braga MM, Raggio DP, Deery C, Ricketts DN, Mendes FM (2013) Fluorescene-based methods for detecting caries lesions: systematic review, meta-analysis and sources of heterogeneity. PLoS One 8:1-14

6. Hibst R, Paulus R, Lussi A (2001) Detection of occlusal caries by laser fluorescence: basic and clinical investigations. Med Laser Appl 16:205-213. https://doi.org/10.1078/1615-1615-00024

7. Douglass CW (1993) Evaluating diagnostic tests. Adv Dent Res 2: 66-69

8. Lussi A, Hellwig E (2006) Performance of a new laser fluorescence device for detection of occlusal caries in vitro. J Dent 34:467-471. https://doi.org/10.1016/j.jdent.2005.11.002

9. Jablonski-Momeni A, Rosen SM, Schipper HM, Stoll R, Roggendorf MJ, Heinzel-Gutenbrunner M, Stachniss V, Pieper K (2012) Impact of measuring multiple or single occlusal lesions on estimates of diagnostic accuracy using fluorescence methods. Lasers Med Sci 27:343-352. https://doi.org/10.1007/s10103-0110881-6

10. Diniz MB, Rodrigues JA, Paula A, Cordeiro RCL (2009) In vivo evaluation of laser fluorescence performance using different cut-off limits for occlusal caries detection. Lasers Med Sci 24:295-300. https://doi.org/10.1007/s10103-008-0547-1

11. Jablonski-Momeni A, Stachniss V, Ricketts DN, HeinzelGutenbrunner M, Pieper K (2008) Reproducibility and accuracy of the ICDAS-II for detection of occlusal caries in vitro. Caries Res 42:79-87. https://doi.org/10.1159/000113160

12. Mitropoulos P, Rahiotis C, Stamatakis H, Kakaboura A (2010) Diagnostic performance of the visual caries classification system ICDAS II versus radiography and micro-computed tomography for proximal caries detection: an in vitro study. J Dent 38:859-867. https://doi.org/10.1016/j.jdent.2010.07.005

13. Soviero VM, Leal SC, Silva RC, Azevedo RB (2012) Validity of MicroCT for in vitro detection of proximal carious lesions in primary molars. J Dent 40:35-40. https://doi.org/10.1016/j.jdent. 2011.09.002

14. Boca C, Truyen B, Henin L, Schulte AG, Stachniss V, De Clerck N, Cornelis J, Bottenberg P (2017) Comparison of micro-CT imaging and histology for approximal caries detection. Sci Rep 7:66-80. https://doi.org/10.1038/s41598-017-06735-6
15. Kamburoğlu K, Kurt H, Kolsuz E, Öztas B, Tatar I, Çelik HH (2011) Occlusal caries depth measurements obtained by five different imaging modalities. J Digit Imaging 24:804813. https://doi.org/10.1007/s10278-010-9355-9

16. Özkan G, Kanli A, Baseren NM, Arslan U, Tatar I (2015) Validation of micro-computed tomography for occlusal caries detection: an in vitro study. Braz Oral Res 29:1-7. https://doi.org/10. 1590/1807-3107bor-2015.vol29.0132

17. Ismail AI, Sohn W, Tellez M, Amaya A, Sen A, Hasson H, Pitts NB (2007) The international caries detection and assessment system (ICDAS): an integrated system for measuring dental caries. Community Dent Oral Epidemiol 35:170-178. https://doi.org/10. 1111/j.1600-0528.2007.00347.x

18. Ekstrand KR, Martignon S, Ricketts DJN, Qvist V (2007) Detection and activity assessment of primary coronal caries lesions: a methodologic study. Oper Dent 32(3):225-235. https://doi.org/ 10.2341/06-63

19. ICCMS ${ }^{\mathrm{TM}}$ Caries Management International Classification and Management System, 2018. https://iccms-web.com/login

20. Hintze H, Wenzel A, Danielsen B, Nyvad B (1998) Reliability of visual examination, fibre- -optic transillumination, and bitewing radiography, and reproducibility of direct visual examination following tooth separation for the identification of cavitated carious lesions in contacting approximal surfaces. Caries Res 32:204-209

21. El-Housseiny AA, Jamjoum H (2001) Evaluation of visual, explorer, and a laser device for detection of early occlusal caries. J Clin Pediatr Dent 26:41-48. https://doi.org/10.17796/jcpd.26.1. ch28322k5837j772

22. Kouchaji C (2012) Comparison between a laser fluorescence device and visual examination in the detection of occlusal caries in children. Saudi Dent J 24:169-174. https://doi.org/10.1016/j.sdentj. 2012.07.002

23. Fagerland MW, Lydersen S, Laake P (2013) The McNemar test for binary matched-pairs data: mid-p and asymptotic are better than exact conditional. BMC Med Res Methodol 13:91. https://doi.org/10.1186/1471-2288-13-91

24. Schisterman EF, Perkins NJ, Liu A, Bondell H (2005) Optimal cut-point and its corresponding Youden index to discriminate individuals using pooled blood samples. Epidemiology 16: 73-81. https://doi.org/10.1097/01.ede.0000147512.81966.ba

25. Francescut P, Zimmerli B, Lussi A (2006) Influence of different storage methods on laser fluorescence values: a two-year study. Caries Res 40:181-185. https://doi.org/10.1159/000092223

26. Kaul R, Kaul V, Farooq R, Dev Vazir N, Ullah Khateeb S, Malik AH, Amin Masoodi A (2014) Cut off values of laser fluorescence for different storage methods at different time intervals in comparison to frozen condition: a one year in vitro study. J Conserv Dent $14: 124-128$

27. Chalas R, Wojcik-Checinska I, Zubrzycka-Wrobel J, Piatek D, Bachanek T (2014) Comparison of visual, impedance spectroscopy and laser fluorescence methods in detecting early lesions on occlusal surfaces. Curr Issues Pharm Med Sci 27: 102-104. https://doi.org/10.2478/cipms-2014-0023

28. Jablonski-Momeni A, Ricketts DNJ, Heinzel-Gutenbrunner M, Stoll R, Stachniss V, Pieper K (2009) Impact of scoring single or multiple occlusal lesions on estimates of diagnostic accuracy of the visual ICDAS-II system. Int $\mathrm{J}$ Dent. https://doi.org/10.1155/2009/798283

29. Braga MM, Oliveira LB, Bonini GA, Bonecker M, Mendes FM (2009) Feasibility of the international caries detection and assessment system (ICDAS II) in epidemiological surveys and comparability with standard world health organization criteria. Caries Res 43:245-249. https://doi.org/10.1159/000217855

30. Achilleos EE, Rahiotis C, Kakaboura A, Vougiouklakis G (2013) Evaluation of a new fluorescence-based device in the detection of 
incipient occlusal caries lesions. Lasers Med Sci 28:193-201. https://doi.org/10.1007/s10103-012-1111-6

31. Ari T, Ari N (2013) The performance of ICDAS-II using lowpowered magnification with light-emitting diode headlight and alternating current impedance spectroscopy device for detection of occlusal caries on primary molars. Hindawi Publishing Corporation ISRN Dentistry, Cairo. https://doi.org/10.1155/2013/276070

32. Castilho LS, Cotta FV, Bueno AC, Moreira AN, Ferreira EF, Magalhães CS (2016) Validation of DIAGNOdent laser fluorescence and the international caries detection and assessment system (ICDAS) in diagnosis of occlusal caries in permanent teeth: an in vivo study. Eur J Oral Sci 124:188-194. https://doi.org/10. 1111/eos. 12257

33. Iranzo-Cortes JE, Terzic S, Montiel-Company JM, Almerich-Silla JM (2017) Diagnostic validity of ICDAS and DIAGNOdent combined: an in vitro study in pre-cavitated lesions. Lasers Med Sci 32: 543-548. https://doi.org/10.1007/s10103-017-2146-5

34. Jablonski-Momeni A, Liebegall F, Stoll R, Heinzel-Gutenbrunner M, Pieper K (2013) Performance of a new fluorescence camera for detection of occlusal caries in vitro. Lasers Med Sci 28:101-109. https://doi.org/10.1007/s10103-012-1080-9

35. Kockanat A, Unal M (2017) In vivo and in vitro comparison of ICDAS II, DIAGNOdent pen, CarieScan PRO and SoproLife camera for occlusal caries detection in primary molar teeth. Eur $\mathrm{J}$ Paediatr Dent 18:99-104

36. Neuhaus KW, Jost F, Perrin P, Lussi A (2015) Impact of different magnification levels on visual caries detection with ICDAS. J Dent 43:1559-1564. https://doi.org/10.1016/j.jdent.2015.09.002
37. Rodrigues JA, Hug I, Diniz MB, Lussi A (2008) Performance of fluorescence methods, radiographic examination and ICDAS II on occlusal surfaces in vitro. Caries Res 42:297-289. https://doi.org/ $10.1159 / 000148162$

38. Reis A, Mendes FM, Angnes V, Angnes G, Grande RH, Loguercio AD (2006) Performance of methods of occlusal caries detection in permanent teeth under clinical and laboratory conditions. J Dent 34: 89-96. https://doi.org/10.1016/j.jdent.2005.04.002

39. Chu CH, Lo ECM, You DSH (2010) Clinical diagnosis of fissure caries with conventional and laser-induced fluorescence techniques. Lasers Med Sci 25:355-362. https://doi.org/10.1007/s10103-009-0655-6

40. Teo TKY, Ashley PF, Louca C (2014) An in vivo and in vitro investigation of the use of ICDAS, DIAGNOdent pen and CarieScan PRO for the detection and assessment of occlusal caries in primary molar teeth. Clin Oral Invest 18:737-744. https://doi. org/10.1007/s00784-013-1021-4

41. Bücher K, Galler M, Seitz M, Hickel R, Kunzelman KH, Kühnisch J (2015) Occlusal caries extension in relation to visual and radiographic diagnostic criteria: results from a microcomputed tomography study. Oper Dent 40(3):255262. https://doi.org/10.2341/13-128-L

Publisher's note Springer Nature remains neutral with regard to jurisdictional claims in published maps and institutional affiliations. 